\title{
Effects of ethanol and ultraviolet-c treatments on inactivation of Rhizopus oryzae spores which cause postharvest rot
}

\author{
Gülsüm Ebru ÖZER UYAR ${ }^{1 \star}$, Başar UYAR ${ }^{2}$
}

\begin{abstract}
Rhizopus oryzae is a filamentous fungi reported as a postharvest pathogen in recent years. Ethanol treatment $(0,10,20$, and $30 \%)$ and UVC irradiation $(0,1,2,5,10$ minutes) were used both individually and in combination for the inactivation of Rhizopus oryzae spores. Survival ratio of the spores and LD50 values for ethanol and UVC irradiation were determined to quantify the germicidal effect. UVC exposure is found to be significantly more effective than ethanol treatment on the reduction of $R$. oryzae spore survivability. The combination of UVC exposure and ethanol treatment enhanced the lethality of applying each treatment separately and the enhancement increased as the UVC exposure time and ethanol concentrations increased. The lowest spore survival ratio was $0.015 \%$, obtained after $30 \%$ ethanol treatment followed by 10 minute of UVC exposure. These observations suggest that ethanol treatment and UVC exposure can effectively be used as a possible strategy to inactivate $R$. oryzae spores.
\end{abstract}

Keywords: Rhizopus oryzae; postharvest rot; ethanol; UVC irradiation.

Practical Application: Ethanol treatment and UVC exposure can effectively be used as a possible strategy to inactivate R. oryzae spores.

\section{Introduction}

There are several methods to control postharvest diseases on fresh food and agricultural products. Chemical treatments are effective but restricted in most countries. In addition, consumers are looking for products free of chemical residues. Consequently, safe alternative control strategies, such as antagonists, natural compounds, and physical treatments have drawn attention (Cia et al., 2007).

Gamma and ultraviolet light irradiations are physical treatments that can be used for the control of postharvest diseases. Besides exhibiting fungicidal effects, these treatments can also induce resistance in fruits (Wilson et al., 1994).

Ultraviolet light (UV) is classified based on wavelength as UVA (320-400 nm), UVB (280-320 nm), UVC (200-280 nm) and UVV (100-200 nm) (Guerrero-Beltrán \& Barbosa-Cánovas, 2004). UV treatment is a physical method which produces neither undesirable by-products nor chemical residues (Keyser et al., 2008), therefore, this technology is widely used in the food industry for disinfection of air, control of contamination on the surface of plants and packaging materials or in post-harvest storage of fruits and vegetables (Begum et al., 2009). The mechanism of UV effect may vary according to species. UV radiation in the range of 250-260 nm is germicidal for most microorganisms, including fungi, yeast, bacteria, viruses, protozoa and algae (Begum et al., 2009).

The UVC germicidal effect is mainly at the nucleic acid level and the mechanism of inactivation is by causing a physical shifting of electrons and breaking of bonds in the DNA (Lopez-Malo \& Palou, 2005).

There are many studies about germicidal effect of UVC on fungi, especially those that cause decay on postharvest products. Botrytis cinerea, Monilinia fructigena, Monilinia fructicola, Penicillium digitatum were reported as postharvest spoilage fungi of some fruits like strawberries, cherries, peaches and tangerine, respectively (Marquenie et al., 2002; Stevens et al., 1997, 1998). Additionally, Liu et al. (1993) showed that Alternaria alternata, B. cinerea and Rhizopus stolonifer which cause tomato diseases, were effectively eliminated by UVC light treatment.

There are variations in the response of fungal species to UV radiation. The UV radiation induces the production of melanin in some fungal species. Melanin is a dark-photoprotective pigment found in animals, plants and microorganisms and increases the survival and longevity of fungal spores (Bell \& Wheeler, 1986). Penicillium janthinellum produces slightly pigmented conidia which are more susceptible to UVC than dark pigmented Aspergillus niger (Valero et al., 2007).

Among chemical treatment methods, immersion of fruits in ethanol solutions has been reported to effectively control postharvest decay caused by fungi (Gabler et al., 2004). The major target of ethanol as a stress agent is the lipid membrane, but it has many other effects on fungal cells. Ethanol lowers the transition temperatures of fungal membrane lipids and increases their fluidity; these interactions are thought to be the mode of 
lethal action of ethanol (Russell \& Furr, 1996). According to Cabeca-Silva et al. (1982), the primary sites of action of both heat and ethanol are mitochondrial membranes.

Lichter et al. (2002) showed that B. cinerea on the table grapes was eliminated by $40 \%$ (v/v) ethanol. Yuen et al. (1995) found that ethanol vapor inhibited decay of oranges caused by Penicillium italicum and $P$. digitatum after 5 days of continuous exposure. The complete inhibition of germination of $B$. cinerea and A. alternata by 30 s exposure to $30 \%(\mathrm{v} / \mathrm{v})$ ethanol at ambient temperature was also reported (Gabler et al., 2004).

Ethanol already occurs in many food products and additives and is an approved substance for use as a disinfectant or sanitizer in organic crop production by USDA National Organic Program (Lichter et al., 2002).

Combining different methods to control postharvest diseases creates a synergistic effect. For example, heat and ethanol treatments are used to control postharvest decay of strawberries caused by B. cinerea and R. stolonifer (Margosan et al., 1994), lemons caused by $P$. digitatum, and peaches and nectarines by Monilinia fructicola (Margosan et al., 1997; Smilanick et al., 1995).

Rhizopus oryzae (Rhizopus arrhizus) is a filamentous fungi which is mainly known as a lactic acid producer. It is also a well known severe postharvest pathogen causing serious problems like soft rot disease in potato (Amadioha, 2001). Also postharvest rot caused by $R$. oryzae has been recorded on various fruits including banana, apple (Kwon et al., 2011, 2012). Another study reported postharvest root rot of Codonopsis lanceolata (a medicinal root crop native to East Asia) by R. oryzae (Park et al., 2014).

The studies on the inhibition of $R$. oryzae spores are very rare: One such study explores the antifungal effects of some leaf extracts against $R$. oryzae. Azadirachta indica (Neem), Cymbopogon citratus, and Ocimum gratissimum leaf extracts proved effective against the spore germination and mycelial growth of $R$. oryzae (Amadioha, 2001).

The aim of this research was to quantify the germicidal effect of UVC and ethanol treatments on R. oryzae spores. To the best of our knowledge, this is the first study to examine the effect of UVC on $R$. oryzae spore germination.

\section{Materials and methods}

\subsection{Microorganism and growth conditions}

In this study, R. oryzae (ATCC 9363) was used. It was sporulated on streaked agar plates containing Potato Dextrose Agar (PDA) for $4-5$ days at $30^{\circ} \mathrm{C}$. After sporulation, the plates were stored at $4{ }^{\circ} \mathrm{C}$ until preparation of spore suspension; spore suspension was prepared by washing the spores with sterile distilled water. Spore concentration in the suspension was determined by counting the spores on hemocytometer.

\subsection{Ethanol treatment and UV-C irradiation}

Spores were collected as described previously. Test tubes were prepared that contained $9 \mathrm{~mL}$ of solution each, to make final concentrations of $0,10,20$, and $30 \%(\mathrm{v} / \mathrm{v})$ ethanol after $1 \mathrm{~mL}$ of spore suspension containing $3.58 .10^{7}$ spores $/ \mathrm{mL}$ of spores was added. The tubes were incubated for 5 minutes at $25^{\circ} \mathrm{C}$, then the solutions were centrifuged for 5 minutes at $25^{\circ} \mathrm{C}$ and $5000 \mathrm{rpm}$. The supernatant was discarded and the spores were washed with sterile distilled water to remove any ethanol residue. After washing, the spores were resuspended in $10 \mathrm{~mL}$ of sterile distilled water.

For UVC irradiation studies $10 \mathrm{~mL}$ of the spore suspensions was carefully poured aseptically in empty sterile petri plates, which had $90 \mathrm{~mm}$. diameter, flat bottom and no lid, then they were placed under a germicidal UV lamp $(2.5 \times 88 \mathrm{~cm})$. The lamp used was rated at $30 \mathrm{~W}$ power and its peak emission was at $254 \mathrm{~nm}$ wavelength. The distance between the lamp and the petri plates was $20 \mathrm{~cm}$. The petri plates were irradiated for various time periods $(0,1,2,5,10$ minutes). Under these conditions the average dose rate was $3.18 \mathrm{~W} / \mathrm{m}^{2}$ and the radiant exposure (dosage) varied from 0.19 to $1.91 \mathrm{~kJ} / \mathrm{m}^{2}$ (Liu et al., 1993; Stevens et al., 1997). After the exposure, they were kept in dark for two hours to prevent photoreactivation (Stevens et al., 1998).

In order to examine the combined effect of ethanol and UVC on the survival ratio of the spores, the treatments mentioned above applied sequentially (first ethanol, followed by UVC) to the spore suspensions of $R$. oryzae.

\subsection{Survival ratio determination}

For determination of the survival ratio, spores were inoculated on agar plates for colony formation. For this purpose, serial dilutions of the treated spore suspensions were made. To obtain a homogeneous suspension between dilutions, the suspensions were shaken for $15 \mathrm{~s}$ using a vortex mixer. Sterile distilled water was used for dilution. One millilitre of each spore suspension was plated on PDA and they were incubated at $30^{\circ} \mathrm{C}$. Formed colonies were counted on 5th day after the inoculation. There were three replicates of plates for each condition, and the experiments were done twice. The control treatment in each experiment was water alone at $25^{\circ} \mathrm{C}$.

Survival ratio of the spores (S) was calculated by Equation 1 (Peleg \& Cole, 2000):

$S=N / N_{0}$

where $\mathrm{N}_{0}$ is the spores' initial number and $\mathrm{N}$ is the number of surviving spores after the exposure to the UVC and/or ethanol treatment.

\subsection{Statistical analysis}

The effects of ethanol and UVC exposure times on spores from $R$. oryzae were statistically analysed using Microsoft Excel (ANOVA two-factor with replication).

To compare the sensitivity of the spores to the treatments, LD50 values which are the concentration of ethanol or duration of UVC treatment that prevented germination of $50 \%$ of fungal spores were calculated. 


\section{Results and discussion}

Figure 1 shows the effect of UVC exposure after ethanol treatment on the survivability of $R$. oryzae spores. In all cases, a rapid inactivation was observed after one minute of UVC exposure, then the rate of reduction in survivability of spores decreased.

The effect of only UVC exposure can also be seen in Figure 1, the topmost line represents the case where spores were not immersed in the ethanol solution. Here, exposure of $R$. oryzae spores to UVC resulted in $1.50 \log _{10}$ reduction after 1 minute of exposure, and a total of $2.20 \log _{10}$ reduction after 10 minute of exposure.

In a comparable study, it has been shown that UV irradiation was very effective at inactivating the spores of A. flavus, $P$. corylophilum and E. rubrum and was also effective against A. niger, although to a lesser extent (Begum et al., 2009).

Another study reported a comparable effect of UVC radiation on five different fungi, the survival fractions were found to decay exponentially (Valero et al., 2007).

First data points of all lines in Figure 1 show the samples where UVC was not applied (UVC exposure time $=0$ ), and demonstrate the effect of only ethanol treatment on the survivability of R. oryzae spores. Every 10\% (v/v) ethanol concentration increase resulted in an average of $0.29 \log _{10}$ reduction, $30 \%(\mathrm{v} / \mathrm{v})$ ethanol treatment resulted in $0.88 \log _{10}$ reduction in survivability of spores. For $50 \%(\mathrm{v} / \mathrm{v})$ ethanol concentration fungal growth was not observed (result not shown).

Our findings are supported by previous literature, it was reported that, at $25^{\circ} \mathrm{C}, 30 \%(\mathrm{v} / \mathrm{v})$ ethanol significantly reduced the percentage of germinated spores of $B$. cinerea and A. alternata, while higher temperatures were required to inhibit the more resistant spores such as $R$. stolonifer and A. niger (Gabler et al., 2004).

It should also be pointed that in fruit postharvest, spores would be more protected by the fruit itself and those treatments may not yield as much inactivation as reported in this study. On the other hand, UVC is a hormetin (stimulatory agent in subharmful doses) which induces resistance to pathogens in postharvest products (Stevens et al., 1997). Therefore the combined fungicidal and hormetic effects of these agents need to be assessed in further applications.

Combination of UVC exposure and ethanol treatment were more effective for reducing the spore viability (Figure 1). Moreover, total efficiency of spore reduction increased when both methods were applied indicating a synergistic effect. For example, one minute UVC exposure alone resulted in $1.50 \log _{10}$ decrease and $10 \%(\mathrm{v} / \mathrm{v})$ ethanol treatment alone resulted in $0.35 \log _{10}$ decrease, whereas $10 \%(\mathrm{v} / \mathrm{v})$ ethanol treatment followed by one minute UVC exposure resulted in $1.92 \log _{10}$ decrease, which is higher than the sum of both methods. This effect is valid for all 12 combinations of UVC and ethanol treatments tested, moreover the efficiency difference increased as the UVC exposure time and ethanol concentrations increased.
This effect was illustrated in Table 1, where for all 12 combinations of UVC and ethanol treatments tested, the difference in efficiency was tabulated. Here, the difference was calculated by Equation 2:

$$
\begin{aligned}
& \text { Efficiency difference }=\left(\begin{array}{l}
\log _{10} \text { decrease for the combined } \\
\text { ethanol and UVC effect }
\end{array}\right)- \\
& {\left[\left(\begin{array}{l}
\log _{10} \text { decrease for } \\
\text { the ethanol only }
\end{array}\right)+\left(\begin{array}{c}
\log _{10} \text { decrease for } \\
\text { the UVC only }
\end{array}\right)\right]}
\end{aligned}
$$

The difference value was positive in all cases with an average of $0.27 \log _{10}$, which shows that the combination of UVC and ethanol is more lethal to the spores than expected. Moreover, the efficiency difference increased up to $0.8 \log _{10}$ as the UVC exposure time and ethanol concentrations increased.

Such synergistic effect was reported in a previous study, in which the combined application of UVC and heat treatment improved on the results found for each treatment separately and reduced the percentage of spore germination to the greatest extent (Pan et al., 2004). Under the tested conditions, the highest reduction of spore survivability was obtained after $30 \%(\mathrm{v} / \mathrm{v})$ ethanol treatment followed by UVC exposure: Here, 5 minutes of exposure resulted in $3.71 \log _{10}$ reduction, and increasing the UVC exposure to 10 minutes improved reduction only marginally to $3.83 \log _{10}$, which corresponds to $0.015 \%$ survival ratio for the spores.

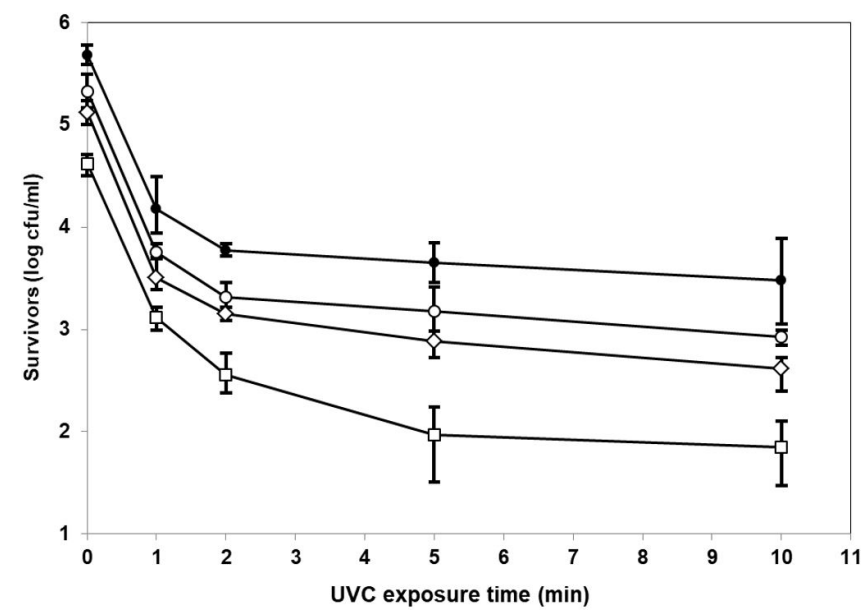

Figure 1. Effect of UVC exposure on spores treated with $0 \%(\mathrm{v} / \mathrm{v})$ ethanol $(\bullet), 10 \%(\mathrm{v} / \mathrm{v})$ ethanol $(\circ), 20 \%(\mathrm{v} / \mathrm{v})$ ethanol $(\diamond)$, and $30 \%$ (v/v) ethanol ( $\square)$.

Table 1. Efficiency difference of $\log _{10}$ decrease in spore survivability for combined EtOH and UVC treatment.

\begin{tabular}{ccccc}
\hline \multirow{2}{*}{ EtOH (\% v/v) } & \multicolumn{4}{c}{ UV-C duration (min) } \\
\cline { 2 - 5 } & 1 & 2 & 5 & 10 \\
\hline 10 & 0.07 & 0.10 & 0.12 & 0.20 \\
20 & 0.11 & 0.06 & 0.21 & 0.30 \\
30 & 0.22 & 0.33 & 0.80 & 0.75 \\
\hline
\end{tabular}



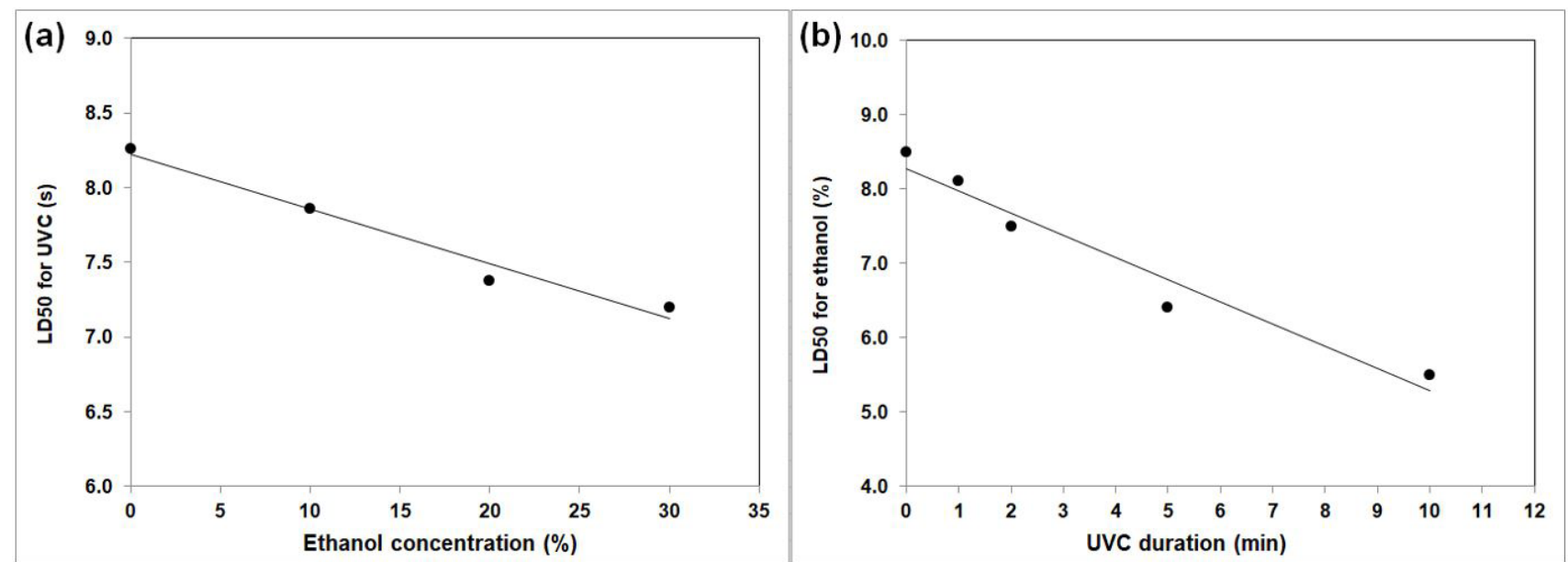

Figure 2. (a) UVC durations that inhibited the germination of $50 \%$ of the spores (LD50) of R. oryzae; (b) Ethanol concentrations that inhibited the germination of $50 \%$ of the spores (LD50) of R. oryzae.

Figure 2a shows the LD50 values of UVC treatment durations at various ethanol concentrations and Figure $2 b$ shows the LD50 values of ethanol concentration at various UVC treatment durations. For every 1 minute increase in UVC treatment, the LD50 value for concentration of ethanol decreased by $0.3 \%$, and for every $10 \%(\mathrm{v} / \mathrm{v})$ increase in ethanol concentration, the LD50 value for the duration of UV-C treatment decreased by 0.35 second.

The combined effect of the two factors can also be seen here, the lines have a negative slope, that is, increase in one factor decreases LD50 (increases lethality) of the other factor.

Both F and P-values show that ethanol content, UVC treatment time and their interactions all were highly significant at the $99 \%$ level of confidence for spores suspended in aqueous medium.

\section{Conclusions}

Ethanol treatment and UVC irradiation were used for the inactivation of $R$. oryzae spores, both individually and in combination. A rapid inactivation of fungal spores was observed after one minute of UVC exposure, then the rate of reduction in survivability of spores decreased, whereas inactivation due to ethanol treatment was directly proportional to the ethanol concentration. The combination of UVC exposure and ethanol treatment enhanced the benefits of applying each treatment separately. The benefits increased as the UVC exposure time and ethanol concentrations increased. Increase in one factor decreases LD50 (increases lethality) of the other factor.

The results of this work support the use of ethanol treatment and UVC exposure as a possible strategy to inactivate R. oryzae spores to prevent postharvest rot.

\section{Acknowledgements}

This work was supported by Kocaeli University Scientific Research Projects Coordination Unit (Project Number: 2014/088).

\section{References}

Amadioha, A. C. (2001). Fungitoxic effects of some leaf extracts against Rhizopus oryzae causing tuber rot of potato. Archiv für Phytopathologie und Pflanzenschutz, 33(6), 499-507. http://dx.doi. org/10.1080/03235400109383372.

Begum, M., Hocking, A. D., \& Miskelly, D. (2009). Inactivation of food spoilage fungi by ultra violet (UVC) irradiation. International Journal of Food Microbiology, 129(1), 74-77. http://dx.doi.org/10.1016/j. ijfoodmicro.2008.11.020. PMid:19059664.

Bell, A. A., \& Wheeler, M. H. (1986). Biosynthesis and function of fungal melanin. Annual Review of Phytopathology, 24(1), 411-451. http://dx.doi.org/10.1146/annurev.py.24.090186.002211.

Cabeca-Silva, C., Madeira-Lopes, A., \& van Unden, N. (1982). Temperature relations of ethanol-enhanced petite mutation in Saccharomyces cerevisiae: mitochondria as targets of thermal death. FEMS Microbiology Letters, 15(2), 149-151. http://dx.doi. org/10.1016/0378-1097(82)90099-4.

Cia, P., Pascholati, S. F., Benato, E. A., Camili, E. C., \& Santos, C. A. (2007). Effects of gamma and UV-C irradiation on the postharvest control of papaya anthracnose. Postharvest Biology and Technology, 43(3), 366-373. http://dx.doi.org/10.1016/j.postharvbio.2006.10.004.

Gabler, F. M., Mansour, M. F., Smilanick, J. L., \& Mackey, B. E. (2004). Survival of spores of Rhizopus stolonifer, Aspergillus niger, Botrytis cinerea and Alternaria alternata after exposure to ethanol solutions at various temperatures. Journal of Applied Microbiology, 96(6), 1354-1360. http://dx.doi.org/10.1111/j.1365-2672.2004.02280.x. PMid:15139929.

Guerrero-Beltrán, J. A., \& Barbosa-Cánovas, G. V. (2004). Advantages and limitations on processing foods by UV light. Food Science \& Technology International, 10(3), 137-147. http://dx.doi. org/10.1177/1082013204044359.

Keyser, M., Müller, I. A., Cilliers, F. P., Nel, W., \& Gouws, P. A. (2008). Ultraviolet radiation as a non-thermal treatment for the inactivation of microorganisms in fruit juice. Innovative Food Science \& Emerging Technologies, 9(3), 348-354. http://dx.doi.org/10.1016/j.ifset.2007.09.002.

Kwon, J. H., Kim, J., \& Kim, W. I. (2011). First report of Rhizopus oryzae as a postharvest pathogen of apple in Korea. Mycobiology, 39(2), 140-142. http://dx.doi.org/10.4489/MYCO.2011.39.2.140. PMid:22783094. 
Kwon, J. H., Ryu, J. S., Chi, T. T. P., Shen, S. S., \& Choi, O. (2012). Soft rot of Rhizopus oryzae as a postharvest pathogen of banana fruit in Korea. Mycobiology, 40(3), 214-216. http://dx.doi.org/10.5941/ MYCO.2012.40.3.214. PMid:23115518.

Lichter, A., Zutkhy, Y., Sonego, L., Dvir, O., Kaplunov, T., Sarig, P., \& Ben-Arie, R. (2002). Ethanol controls postharvest decay of table grapes. Postharvest Biology and Technology, 24(3), 301-308. http:// dx.doi.org/10.1016/S0925-5214(01)00141-7.

Liu, J., Stevens, C., Khan, V. A., Lu, J. Y., Wilson, C. L., Adeyeye, O., Kabwe, M. K., Pusey, P. L., Chalutz, E., Sultana, T., \& Droby, S. (1993). Application of ultraviolet-C light on storage rots and ripening of tomatoes. Journal of Food Protection, 56(10), 868-872. http://dx.doi. org/10.4315/0362-028X-56.10.868.

Lopez-Malo, A., \& Palou, E. (2005). Ultraviolet light and food preservation. In G. V. Barbosá-Cánovas, M. S. Tapia \& M. P. Cano (Eds.), Novel food processing technologies (pp. 405-421). Boca Raton: CRC Press.

Margosan, D. A., Smilanick, J. L., \& Simmons, G. F. (1994). Hot ethanol treatment for the postharvest control of gray mold and black rot of strawberries. Biological and Cultural Tests, 10, 60.

Margosan, D. A., Smilanick, J. L., Simmons, G. F., \& Henson, D. J. (1997). Combination of hot water and ethanol to control postharvest decay of peaches and nectarines. Plant Disease, 81(12), 1405-1409. http:// dx.doi.org/10.1094/PDIS.1997.81.12.1405.

Marquenie, D., Lammertyn, J., Geeraerd, A. H., Soontjens, C., Van Impe, J. F., Nicolai, B. M., \& Michiels, C. W. (2002). Inactivation of conidia of Botrytis cinerea and Monilinia fructigena using UV-C and heat treatment. International Journal of Food Microbiology, 74(1-2), 27-35. http://dx.doi.org/10.1016/S0168-1605(01)00719-X. PMid:11930952.

Pan, J., Vicente, A. R., Martínez, G. A., Chaves, A. R., \& Civello, P. M. (2004). Combined use of UV-C irradiation and heat treatment to improve postharvest life of strawberry fruit. Journal of the Science of Food and Agriculture, 84(14), 1831-1838. http://dx.doi.org/10.1002/ jsfa.1894.

Park, J. H., Cho, S. E., Kim, B. S., \& Shin, H. D. (2014). First report of postharvest root rot caused by Rhizopus oryzae on Codonopsis lanceolata. Australasian Plant Disease Notes, 9(1), 135. http://dx.doi. org/10.1007/s13314-014-0135-0.

Peleg, M., \& Cole, M. B. (2000). Estimating the survival of Clostridium botulinum spores during heat treatments. Journal of Food Protection, 63(2), 190-195. http://dx.doi.org/10.4315/0362-028X-63.2.190. PMid:10678423.

Russell, A. D., \& Furr, J. R. (1996). Biocides: mechanisms ofantifungal action and fungal resistance. Science Progress, 79(Pt 1), 27-48. PMid:8693327.

Smilanick, J. L., Margosan, D. A., \& Henson, D. J. (1995). Evaluation of heated solutions of sulfur dioxide, ethanol, and hydrogen peroxide to control postharvest green mold of lemons. Plant Disease, 79(7), 742-747. http://dx.doi.org/10.1094/PD-79-0742.

Stevens, C., Khan, V. A., Lu, J. Y., Wilson, C. L., Pusey, P. L., Igwegbe, E. C. K., Kabwe, K., Mafolo, Y., Liu, J., Chalutz, E., \& Droby, S. (1997). Integration of ultraviolet (UV-C) light with yeast treatment for control of post harvest storage rots of fruits and vegetables. Biological Control, 10(2), 98-103. http://dx.doi.org/10.1006/bcon.1997.0551.

Stevens, C., Khan, V. A., Lu, J. Y., Wilson, C. L., Pusey, P. L., Kabwe, M. K., Igwegbe, E. C. K., Chalutz, E., \& Droby, S. (1998). The germicidal and hormetic effects of UV-C light on reducing brown rot disease and yeast microflora of peaches. Crop Protection, 17(1), 75-84. http:// dx.doi.org/10.1016/S0261-2194(98)80015-X.

Valero, A., Begum, M., Leong, S. L., Hocking, A. D., Ramos, A. J., Sanchis, V., \& Marín, S. (2007). Effect of germicidal UVC light on fungi isolated from grapes and raisins. Letters in applied microbiology, 45(3), 238-243. http://dx.doi.org/10.1111/j.1472-765X.2007.02175.x. PMid:17718833.

Wilson, C. L., El-Ghaouth, A., Chalutz, E., Droby, S., Stevens, C., Lu, J. Y., Khan, V., \& Arul, J. (1994). Potential of induced resistance to control postharvest disease of fruits and vegetables. Plant Disease, 78(9), 837-843. http://dx.doi.org/10.1094/PD-78-0837.

Yuen, C. M. C., Paton, J. E., Hanawati, R., \& Shen, L. O. (1995). Effect of ethanol, acetaldehyde and ethyl formate on the growth of Penicillium italicum and P. digitatum on oranges. Journal of Horticultural Science, 70(1), 81-84. http://dx.doi.org/10.1080/14620316.1995.11515276. 